\title{
JUGANDO EN EL SANATORIO DURÁN: ENTRE LA EXCLUSIÓN Y LA INCLUSIÓN SOCIAL
}

\author{
Playing in the Durán Sanatorium: \\ between exclusion and social inclusion
}

\author{
Pablo Barquero Morice \\ Universidad de Costa Rica, Costa Rica \\ pablo.morice11@gmail.com
}

Recibido: 16-02-2017

Aprobado: 04-05-2017

\begin{abstract}
Pablo Barquero Morice, licenciado en Antropología con énfasis en Antropología Social, Universidad de Costa Rica. Actualmente cursa la Maestría Académica en Historia de la Universidad de Costa Rica. Desde el 2013 imparte cursos libres en la Universidad de Costa Rica sobre la historia del Sanatorio Carlos Durán Cartín.
\end{abstract}

\section{RESUMEN}

El Sanatorio Carlos Durán Cartín siempre estuvo bajo los prejuicios y estigmas de la tuberculosis. Sin embargo, los vecinos del lugar cuentan una historia muy diferente. Usando una interpretación fotográfica se busca acercarse a esa historia de los barrios del Sanatorio.

Palabras clave: inclusión social; fotografía; niñez; Sanatorio Durán

\section{ABSTRACT}

The Carlos Durán Cartín Sanatorium was always under the prejudices and stigmas of tuberculosis. However, the neighbors tell a very different story. Using a photographic interpretation seeks to approach this history of the neighborhoods of the Sanatorium.

Keywords: childhood; Durán Sanatorium; photography; social inclusion

\section{Introducción}

El Sanatorio Carlos Durán Cartín, ubicado en los terrenos aledaños a las faldas del Volcán Irazú, se crea producto de una necesidad: tener un sitio especializado donde albergar personas enfermas de tuberculosis, sin importar edad o condición social.

Este lugar se convierte en un "nuevo mundo" para quienes cayeron en las garras de la "peste blanca"1 pues toca acomodarse a convivir en sociedad,

\footnotetext{
1 Nombre que se le atribuía también a la tuberculosis en contraposición a la "peste negra", relacionada con la peste bubónica; a su vez, el llamarla "peste blanca" se debía a los síntomas que
} 
con personas nuevas y en un lugar, para muchos, muy distinto a donde vivían.

De igual manera para las comunidades aledañas, también se convirtió en un giro de $180^{\circ}$ dentro de sus vidas, pues este lugar, llegó a cambiar bastante la cotidianidad a la que diariamente se enfrentaban.

El Sanatorio Durán, fue el centro de investigación de mi seminario de graduación, para obtener el título de licenciado en Antropología con énfasis en Antropología Social, por lo que, utilizando una de las tantas fotografías a las que pude tener acceso para recrear la dinámica social existente dentro de ese inmueble, buscaré interpretar la misma desde una visión de la exclusión e inclusión social que se daba en el lugar.

\section{Viviendo entre montañas}

Para 1915, producto de un esfuerzo conjunto entre el Dr. Carlos Durán Cartín y el licenciado Manuel Coto Fernández, el gobierno del presidente Alfredo González Flores, decide crear una ley por la cual se construya: "(...) un sanatorio que albergue, aísle y procure la curación de los enfermos de tuberculosis." (Barquero, Mena y Rojas, 2011, p. 1).

No obstante, varios años antes, algunas personas habían solicitado la construcción de un centro para tuberculosos pero no tuvieron el éxito político que sí lograron el Dr. Durán y el Lic. Coto. ${ }^{2}$

La construcción del inmueble dura aproximadamente 3 años, pues el mismo abre sus puertas el 1 de noviembre de 1918 bajo el nombre de Sanatorio Carit ${ }^{3}$ con capacidad para 80 pacientes (40 hombres y 40 mujeres), divididos por género en dos alas. La duración en su construcción

padecían los enfermos y que aparecían conforme avanzaba la enfermedad (Barquero, Mena y Rojas, 2011).

2 En la Gaceta Médica de Costa Rica, Año 8. No. 12, de setiembre de 1904, en la sección de Editorial (223-224) aparece este escrito: "Ha sido propuesto últimamente á la Municipalidad de San José, por un Médico joven, ansioso del bien de la Patria, que se cree en lugar á propósito, en Atenas, Vista de la Mar, Tierra Blanca ú otro, un Sanatorio de Tuberculosos." El médico al cual se hace alusión es el señor Luis Paulino Jiménez, quien, 11 años antes de que se formule la ley para construir el Sanatorio, ya visualizaba la necesidad de crear uno en el país para combatir la enfermedad.

${ }^{3}$ Aunque dentro de la búsqueda informativa, no aparece con claridad el porqué se le coloca este nombre, siempre he tenido la hipótesis que el Dr. Durán influye para que se le llame así producto de: o una gran amistad con el Dr. Adolfo Carit Eva, o por una noción de médico-mentor, en el cual, al ponerle su nombre a la nueva edificación, le rinde homenaje por su labor al servicio del país. 
se debió a la lejanía donde se instaló el lugar y a lo complicado que era el transporte de los materiales desde los distintos centros poblacionales ${ }^{4}$.

No es hasta 1931, cuando el presidente Cleto González Víquez, decide reformar la ley $N^{\circ} 58$ de la creación del Sanatorio para tuberculosos, y lo nombra Sanatorio Durán (Barquero, Mena y Rojas, 2011, p. 13).

Conforme pasaba el tiempo, el Sanatorio iba creciendo en cantidad de edificios y de pacientes; ya no sólo estaban los dos pabellones respectivos para mujeres y hombres, para la década de 1930, se cuenta con dos edificios dedicados a los pensionistas (uno para mujeres y otro para hombres), otro de dos plantas para los niños y las niñas, con su respectiva escuela y lugares de recreo y esparcimiento, así como la ampliación de los pabellones de mujeres y hombres para dar cabida a más personas enfermas (Barquero, Mena y Rojas, 2011, p. 186)

Desde finales de esta década, el Sanatorio toma auge en la medicina costarricense, incluso posicionándolo como un lugar de avanzada en el trato de la tuberculosis a nivel Centroamericano y catalogado como un centro de excelencia a nivel latinoamericano, o sea, era un Sanatorio de primer mundo colocado en Costa Rica 5 .

En los primeros años de la década de 1950, los avances en la medicina mundial que venían presentándose años anteriores en cuanto al combate de la tuberculosis, comenzaron a presentarse en Costa Rica, rayos $\mathrm{X}$, flouroscopías, operaciones de tórax, entre otras; todas estas enfocadas en la pronta detección de la enfermedad y en la curación de la misma. Pero la principal fue la vacuna B.C.G. la cual permitía que la tuberculosis fuera curable desde edades tempranas y se tratara a los pacientes de manera ambulatoria, por lo cual, ya no pesaba tanto la necesidad de internamiento, para la cura de la enfermedad (Barquero, Mena y Rojas, 2011).

Esta situación fue la clave principal para que el Sanatorio Carlos Durán Cartín cerrara sus puertas a finales de 1972 y comienzos de 1973, pues el cierre oficial se da cuando el 9 de febrero de 1973, se traspasa los terrenos que albergaban el Sanatorio, del Ministerio de Salubridad Pública al

\footnotetext{
${ }^{4}$ El Sanatorio se instala $5 \mathrm{Km}$ arriba de Tierra Blanca de Cartago, a $2335 \mathrm{msnm}$; este lugar había sido uno de los señalados por el Dr. Luis Paulino Jiménez en 1904 con posibilidad de albergar el nosocomio producto de la ayuda económica que iba a aportar la Municipalidad de Cartago (ayuda que al final nunca apareció al momento de su construcción).

${ }^{5}$ Solano, 2004; Velásquez, 2008; Barquero, Mena y Rojas, 2011.
} 
Ministerio de Gobernación, Policía, Justicia y Gracia; colocando en las instalaciones un centro de Adaptación Social para jóvenes varones.

\section{Las personas que habitaban sus aposentos}

A lo largo de los 55 años que estuvo en funcionamiento (1918-1973), el Sanatorio vio pasar gran cantidad de personas, las cuales, conforme se integraban a la dinámica social del lugar, pasaban a agruparse en diferentes categorías sociales (médicos, hermanas de la caridad, empleados y pacientes), todas centralizadas por la jerarquía del sitio (Barquero, Mena y Rojas, 2011, p. 365).

Estas personas hacían que el Sanatorio pudiera funcionar, pues al ser autosuficiente, producto de las distancias a los centros poblacionales, el mismo producía un gran porcentaje de lo que se consumía. Incluso, esta situación formaba parte de la "cura de trabajo" (Solano, 2004), la cual, entre muchas cosas, servía para mantener en actividad a las personas menos enfermas que podían realizar labores agropecuarias.

El Sanatorio desde su creación funcionaba como un sitio de exclusión social para quien se encontrara enfermo de tuberculosis, ya que, la estigmatización de la enfermedad ${ }^{6}$ y la lejanía, hacía que muchos pacientes no recibieran visitas de sus amigos o parientes ${ }^{7}$, por lo que se estrecharon en demasía los lazos que unían estas jerarquías sociales.

No obstante, en las comunidades aledañas al Sanatorio, esta estigmatización no tenía el mismo efecto, y más bien, el lugar y las personas que lo habitaban, comenzaban a formar parte de su propia cotidianidad. Debido a que estas comunidades se fueron creando de la mano del Sanatorio. (Barquero, Mena y Rojas, 2011, pp. 400-406).

Esta situación hacía que convivieran en total hermandad, las comunidades cercanas y el Sanatorio, ya que su relación era de uso mutuo, o sea, si el Sanatorio necesitaba personal para las labores diarias, se contrataba gente

\footnotetext{
${ }^{6}$ Uno de los síntomas más estigmatizados de la enfermedad es la expectoración de sangre, por lo que cualquier persona que apareciera tosiendo en público o anduviera con un pañuelo en la mano, era prejuiciada de contraer la "peste blanca".

7 En algunos casos sucedía que las familias se "partían", pues uno de los padres de familia se enfermaba, pasaba meses internado en el Sanatorio y cuando salía, su pareja había formado otra relación; también se dieron casos donde ambos padres enfermaban y los hijos les tocaba valerse por sí mismos a edades muy tempranas, o en su defecto, ser trasladados al Preventorio para convertirse, en cuestión de días, en "huérfano" más.
} 
de la zona, y si estas personas necesitaban medicinas o ser atendidas con urgencia, visitaban a los doctores del Sanatorio, quienes muy amablemente daban ese servicio dentro o fuera de las instalaciones. Por eso, dentro del mundo de exclusión social que encerraba al Sanatorio, había otro de inclusión social con los vecinos y vecinas del lugar, conduciendo a olvidar prejuicios y estigmas creados por la sociedad.

\section{Capturando la vida: los niños y niñas en el Sanatorio Durán}

Al formar esta vecindad de la cual el Sanatorio era el eje central para todos, las celebraciones se volvían casi de carácter público, es decir, se invitaba a las comunidades a participar.

Los vecinos ponían su granito de arena con tal de tener algo maravilloso que celebrar; normalmente esas actividades se daban en fechas específicas: Día del Niño, 15 de setiembre, Navidad, fin de año, Día de reyes, Semana Santa, etc. ${ }^{8}$, se buscaba que la niñez de la zona tuviera ratos de esparcimiento en los cuales compartir con los demás niños y niñas que se encontraban habitando en el Sanatorio, y de alguna manera, hacer olvidar esa exclusión social existente producto de la estigmatización que imperaba sobre el lugar.

La fotografía seleccionada para analizar, fue tomada en una de estas actividades pero no deseo adelantarme a los hechos y comenzaré por la muestra de la fotografía (ver figura $N^{\circ} 1$ ).

\footnotetext{
8 También existían celebraciones de carácter un poco más privado como los bautizos o las primeras comuniones hechas en la Capilla del Sanatorio, en las cuales se daba la participación de la comunidad.
} 


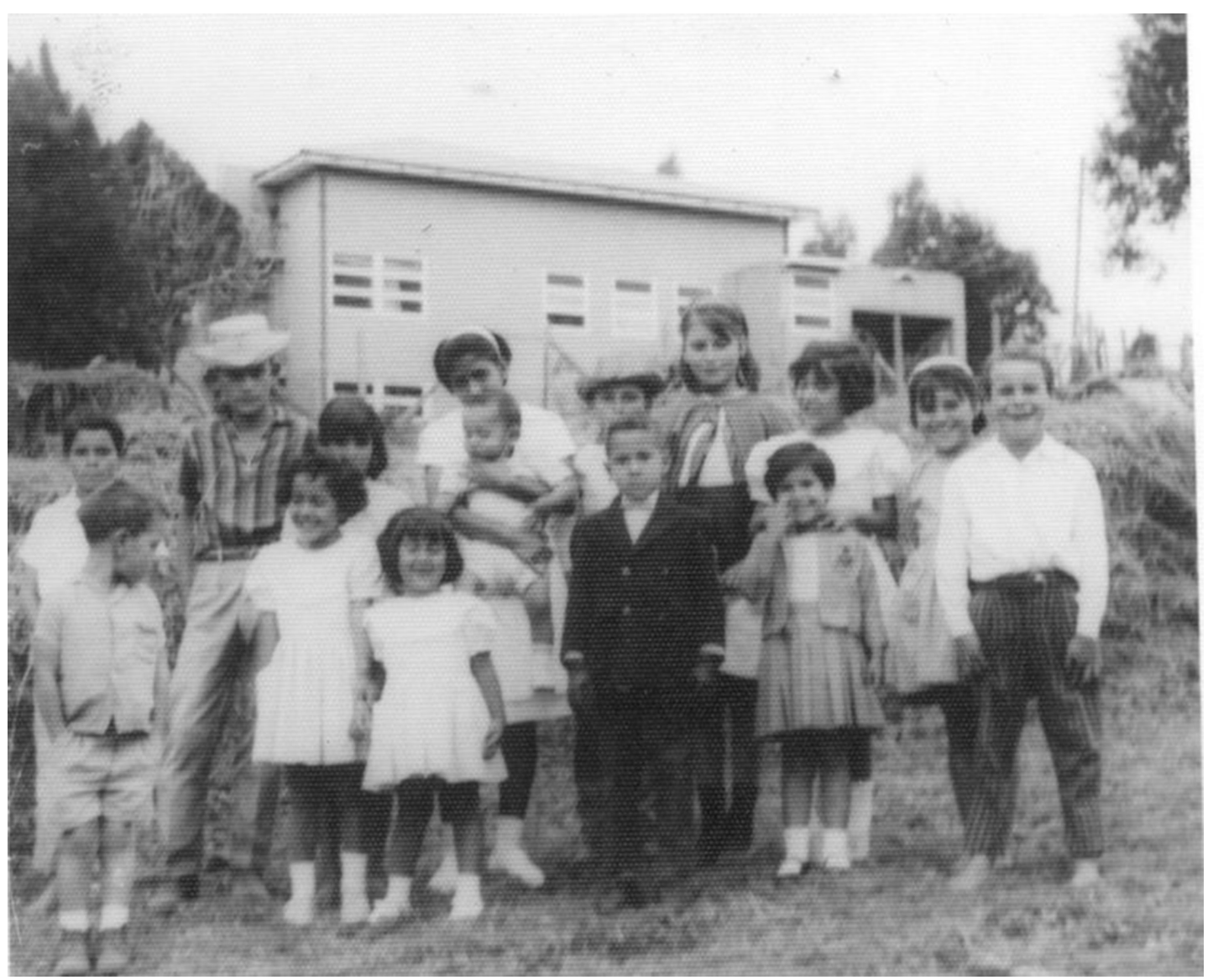

Figura N ${ }^{0}$ 1. Niños y niñas posando en el Sanatorio Durán. Fotografía cortesía de Aida Meza López.

Esta imagen cuenta con bastantes elementos que pueden confundir o desviar el tema principal a la hora de la interpretación.

De primera entrada, se puede apreciar una fotografía donde aparecen 15 personas, con edades que van posiblemente de los 3 años a los 22 años. Aunque la mayoría no supera los 12 años; fue tomada afuera de una edificación, en una zona verde y porque no, en horas de la tarde.

Se nota las diferencias en los vestuarios de estos, aunque algunas de las niñas "repiten" en el sentido de andar con vestidos cortos y de colores claros, no sucede lo mismo con los niños, pues vemos desde los pantalones cortos con camiseta de botones, hasta el traje de saco, pantalón largo y corbatín.0

De los 15, 10 están mirando hacia la cámara, una de las niñas cerró los ojos al tomarse la fotografía, de manera que no mira a la cámara y los 4 restantes miran a diferentes partes del lugar. 
De estos 10 que miran hacia la cámara, hay 4 que se puede percibir claramente que sonríen, 2 tienen tapada la boca por algún objeto en la foto, por lo que no se sabe si están sonriendo o no, y los 4 restantes miran con seriedad, o incluso asombro, hacia la toma de la imagen.

\section{Reinterpretando la imagen}

Cuando el Dr. Raúl Blanco Cervantes se hace cargo de la dirección del Sanatorio Carlos Durán Cartín, a comienzos de la década de 1930, entre las tantas decisiones que toma, una de ellas fue construir casas donde habitaran los médicos, y así no tuvieran que trasladarse como mínimo, desde Cartago o San José, para atender una vez por semana a los enfermos.

Se construyen 3 casas para médicos residentes y una para el médico director, esta última además, es la que tiene mayor espacio pues cuenta con dos plantas, un sótano y una terraza desde la cual se podía observar casi la totalidad del Sanatorio.

Con el paso de los años y al bajar la cantidad de niños y niñas internadas en el Sanatorio, el espacio donde estaba la Escuela se convierte en una nueva casa para médicos residentes, pasando la Escuela a una habitación más pequeña; esto sucede a mediados de la década de 1950.

Para la década de 1960, el Dr. Nicolás Meza Páez, se traslada a trabajar en el Sanatorio, primero como médico residente y luego como el médico director del lugar?. Desde que se levantan estas casas, los médicos residentes que estaban casados y tenían hijos, podían traerlos a vivir con ellos, para no separarse de su familia. El Dr. Meza no pierde la oportunidad y desde el comienzo se lleva a su familia para sentirse más acompañado.

La fotografía que forma parte de este documento pertenece a una de sus hijas: Aida Meza López, quien muy amablemente me cedió esa y otras imágenes sobre el Sanatorio.

La edificación que aparece atrás de los niños y niñas, es la casa del médico director, o sea, la más grande, vista desde el costado este de la propiedad, o el lado derecho si se estuviera frente a esta. Se puede observar los árboles de diferentes especies que rodeaban la propiedad y la totalidad

\footnotetext{
9 El Dr. Meza Páez se convierte en el médico Director que le toca "cerrar" el Sanatorio en 1973 al darse el traslado de los terrenos como se mencionaba en párrafos anteriores.
} 
del Sanatorio; incluso la mayoría eran de Eucalipto, pues dentro de la "cura sanatorial" presente a nivel mundial, se consideraba como una buena terapia que los pacientes respiraran la fragancia que dejaba el eucalipto en el ambiente.

También aparece la entrada al garaje de la propiedad; esta era la única casa que contaba con ese detalle, una idea entre lujo y necesidad que permitía a quien fuera el médico director, tener su transporte propio para trasladarse con mayor facilidad fuera del Sanatorio Carlos Durán Cartín.

Sobresaliendo del techo, se mira una especie de "mancha" u objeto movido, que alguien puede llegar a interpretar con la silueta de una persona; sin embargo, ese objeto en movimiento, no es más que una de las copas de los árboles del bosque cercano al pabellón de pensionados, el cual estaba a cierta distancia de la casa del médico director.

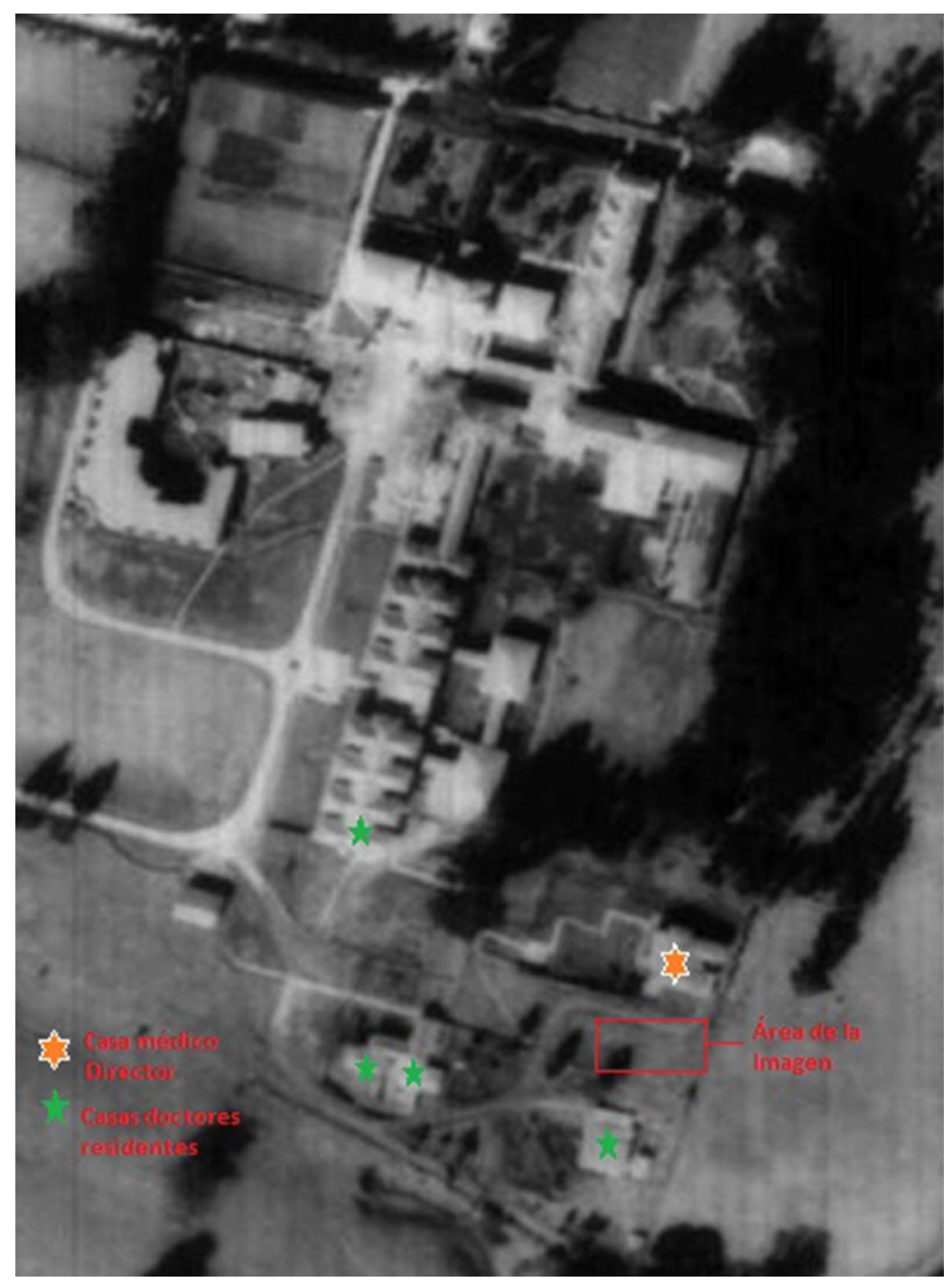

Figura № 2. Fotografía aérea IGN, 1966. Composición: Pablo Barquero Morice. 2017. 
La imagen anterior (ver figura $N^{\circ} 2$ ), permite recrear el espacio específico donde fue tomada la fotografía; se nota que el mismo se encontraba rodeado por las casas de los médicos, o sea, un espacio que perfectamente podría convertirse en una "zona de seguridad" para estos niños, pues se encontraban a la vista de todos los médicos y sus familiares. Pero ¿qué actividad se estaba realizando para reunir a esa cantidad de niños y niñas?

La celebración que reunió a esa cantidad de pequeños y pequeñas fue el cumpleaños de Nicolás Meza, hijo del médico director del Sanatorio, el Dr. Nicolás Meza Páez; para la actividad se invitó a los niños y niñas de la comunidad que tuvieran alguna relación de amistad con el festejado y sus hermanas.

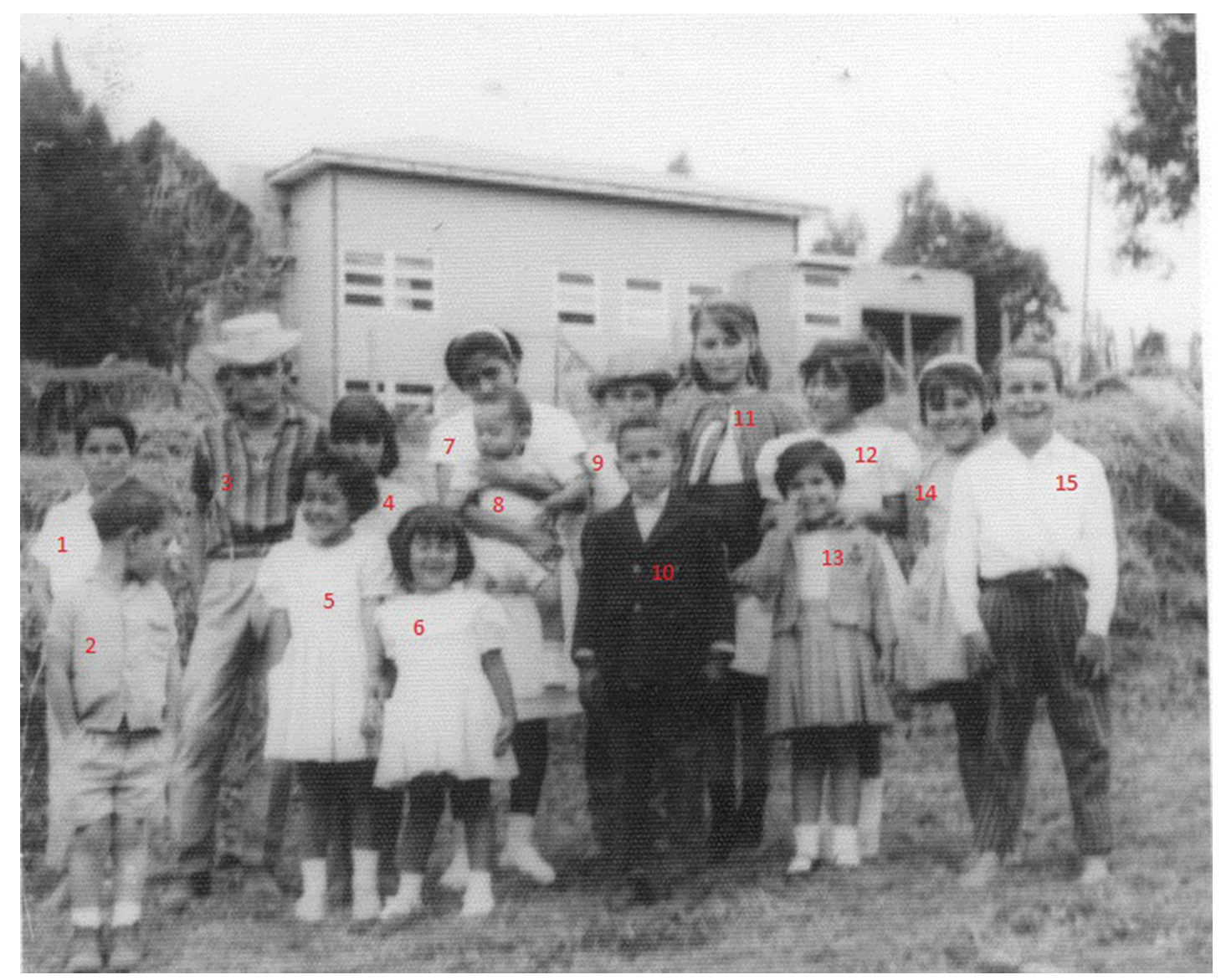

Figura № 3. Niños y niñas posando en el Sanatorio Durán. Cortesía de Aida Eugenia Meza López. Composición: Pablo Barquero Morice. 2017. 
Por eso aparecen en la imagen con lo que puede ser sus mejores galas; claro está, algunas difieren dependiendo del acceso económico que sus familias tuvieran, incluso se podría llegar a pensar en que sus vestimentas no están precisamente hechas para jugar y divertirse "pegando brincos o rodando por la tierra" pero no se debe perder de vista que estaban siendo invitados al cumpleaños del hijo del director del Sanatorio, por lo que se debía tratar de llegar de la mejor manera posible.

El homenajeado, de acuerdo al número colocado en la imagen, es el niño 10; sin embargo, también la 4, 5, 12 y el 8, eran hijos del médico director. El resto son hijos de familias vecinas de la zona, quienes también desde su cotidianidad compartían lazos con quienes habitaban el Sanatorio.

Caso aparte debe recibir la persona que lleva el número 7, pues aunque parece ser joven, por su vestimenta, que presenta una especie de doble tela, bajo el zapato del bebé que carga, es posible que fuera una de las empleadas del Sanatorio, que en ese instante se encontraba haciendo el papel de niñera del bebé, para que éste estuviera con los demás niños. Es sumamente interesante el gesto de su mano izquierda, tratando de hacer que el bebé girara su cabeza para que saliera mirando hacia el frente en la foto, olvidándose ella de "salir bien" en la misma, con tal de que el bebé quedara retratado como merece, pues al final de cuentas es el bebé de sus patrones.

Por el orden que presentan los involucrados en la misma, se nota que fueron pedidos a solicitud del fotógrafo, para "inmortalizar" el momento, incluso y por la sonrisa de la mayoría, cabe la posibilidad que antes de tomar la imagen, les hiciera alguna broma o les dijera un comentario vacilón o un chiste para que se reflejara la alegría del día y del lugar. Ejemplo de esto puede ser el gesto que tiene la niña 13, al llevarse el dedo índice de su mano derecha hacia su ojo derecho, mientras sonríe, como una idea de indicar que estaba viendo hacia la cámara o hacia "el pajarito" como se decía a veces antes de tomar la fotografía.

No obstante, cabe resaltar a dos niños que sus acciones plasmadas en la fotografía difieren mucho de la camaradería que se aprecia en ésta, estos son el niño 2 y el 10 . En el caso del 2, su gesto de tener las manos en la bolsa y no estar preparado para la imagen, puede hacer pensar que no se encontraba acostumbrado a ser fotografiado pues se debe recordar que para finales de 1960 y comienzos de 1970 no cualquiera tenía acceso a una cámara fotográfica, y por algo fue pillado "in fraganti" viendo a la niña 6 o al niño 10. Sobre el niño 10, por su gesto serio y educado, es muy 
probable que fuera uno de sus padres, quien toma la fotografía, por lo que debe aparecer serio ante la imagen, pues él es el hijo del médico director y además el homenajeado de la actividad.

\section{Conclusión}

El mundo que giraba en torno a la tuberculosis estaba lleno de estigmatización y dolor. Dolor por la separación familiar, por cargar con una enfermedad, por quedar bajo los chismes y el qué dirán de la comunidad donde vivía alguna persona que contrajo tuberculosis y lo tuvieron que llevar al Sanatorio, o sea, una exclusión social perenne.

La exclusión que vivían las comunidades aledañas al lugar era de tipo económico, al ser netamente agrícolas, sus niveles de ingresos no eran tan altos y en algunos casos apenas daba para sobrevivir el día a día. Sumado a eso, la escolaridad era bastante baja pues para la época de la imagen, en los alrededores solo se contaba con 2 escuelas y ningún colegio, por lo que si alguien decidía seguir la educación secundaria, debía trasladarse a Cartago centro o a San José, con el costo que implicaba eso.

Dos puntos excluidos por una sociedad que veían su inclusión al unirse para distintas actividades festivas dentro de la comunidad llamada: Sanatorio Carlos Durán Cartín. La algarabía y la alegría podían borrar las lágrimas y la tristeza de los rostros, de quienes una vez estuvieron viviendo en el Sanatorio, así mismo, de todas aquellas personas que fueron vecinas del hoy casi abandonado inmueble, pues en ese instante se olvidaba todo y se vivía en la realidad que tenía el Sanatorio. 


\section{BIBLIOGRAFÍA}

Barquero, Pablo; Mena, Faridy y Rojas, Monserrat. (2011) El Sanatorio Carlos Durán Cartín (1918-1973), Cartago, Costa Rica: una aproximación desde la Antropología Social y la Arqueología. Trabajo Final de Graduación para optar a la licenciatura en Antropología con énfasis en Antropología Social y Arqueología, Universidad de Costa Rica, Facultad de Ciencias Sociales, Escuela de Antropología.

Instituto Geográfico Nacional. (1966) Fotografía aérea, zona: Sanatorio Durán, alrededores Volcán Irazú.

Rucavado, Francisco J. (1904) "Proyecto Humanitario" En: Gaceta Médica de Costa Rica. 8, no. 12 (1904): 223-224. http://www.sinabi.go.cr/Biblioteca\%20Digital/REVISTAS/ Gaceta\%20Medica\%20de\%20Costa\%20Rica/Gaceta\%20Medica\%20de\%2 0Costa\%20Rica\%201904/h-La\%20Gaceta\%20medica_set_1904.PDF

Solano, Vivian. (2004) La tuberculosis y la cura sanatorial en Costa Rica: el caso del Sanatorio Carlos Durán, 1915-1940. Trabajo Final de Graduación para optar a la Maestría Profesional en historia. Universidad de Costa Rica, Sistema de Estudios de Posgrado, Maestría Profesional en Historia.

Velásquez, Carmela. (2008) "Tierra Blanca una montaña de esperanza en la cura de la tuberculosis." Ponencia presentada en el Noveno Congreso Centroamericano de Historia. 